\title{
Public reactions to direct-to-consumer genetic health tests: A comparison across the US, UK, Japan and Australia
}

\author{
Jan Charbonneau ${ }^{1}$ Dianne Nicol $\oplus^{1} \cdot$ Don Chalmers $^{1} \cdot$ Kazuto Kato $^{2} \cdot$ Natsuko Yamamoto $^{2} \cdot$ Jarrod Walshe $^{3}$. \\ Christine Critchley ${ }^{1,3}$
}

Received: 8 February 2019 / Revised: 4 September 2019 / Accepted: 8 October 2019 / Published online: 23 October 2019

(c) The Author(s), under exclusive licence to European Society of Human Genetics 2019

\begin{abstract}
While direct to consumer health-related genetic testing (DTCGT) has potential to provide accessible genetic information and empower individuals to make informed healthcare decisions, it attracts concern associated with regulatory gaps, clinical utility and potential for harm. Understanding public reactions to DTCGT is vital to facilitate considered regulatory, health care and consumer protection strategies. Yet little is known, particularly outside the dominant US market, about how the general public view and might engage with DTCGT outside traditional health care systems. This paper addresses this knowledge gap with the first empirical study to investigate general public views across four countries, each at different stages of market development. US $(n=1000)$, UK $(n=1014)$, Japanese $(n=1018)$ and Australian $(n=1000)$ respondents completed an online experimental survey assessing comprehension, risk perceptions, and potential psychological and behavioural outcomes by type of test (disease pre-disposition and drug sensitivity), severity, lifestyle factors, and family history. Results showed generally low awareness and intention to purchase across countries, highest in the US and lowest in Japan. Results also showed clear preference for within-country purchases (less in Japan), with reports returned via doctors far more important in Japan. All respondents were more likely to act on test results, where there was higher genetic or lifestyle risk of developing a disease. Statistical comparisons of demographic and health-related variables across countries point to the need for further analyses designed to explain much needed cross-cultural, cross-health care system and developed versus developing market differences.
\end{abstract}

\section{Introduction}

From the outset, commercial DNA testing has been controversial, with the first entrants criticised for 'selling the imprimatur of science', invoking 'science's power without accepting its limits' and failing to make clear 'the

Supplementary information The online version of this article (https:// doi.org/10.1038/s41431-019-0529-8) contains supplementary material, which is available to authorised users.

Jan Charbonneau

jan.charbonneau@utas.edu.au

1 Centre for Law \& Genetics, University of Tasmania, Hobart, TAS, Australia

2 Department of Biomedical Ethics and Public Policy, Graduate School of Medicine, Osaka University, Osaka, Japan

3 Department of Statistics, Data Science and Epidemiology, Swinburne University of Technology, Melbourne, VIC, Australia limitations and potential dangers' [1]. Since a major DTCGT company invited Americans to its first online 'spit party' in 2007, [2] the controversy has intensified, with direct-to-consumer health-related genetic testing (DTCGT) deemed 'one of the most promising, yet controversial medical advances of the modern era' [3] and viewed as a major aspect of the age of personalised medicine [4]. Yet DTCGT has potential as 'a powerful mechanism for providing comprehensive genomic information to a large number of individuals' [3], capable of fostering consumer empowerment [5] relative to healthcare and lifestyle decision-making [6], without further diminishing limited public healthcare resources. Industry advocates argue DTCGT enables 'individuals to learn about the basics of genetics through the lens of their own data' with affordable and easily accessible test results serving as a 'foundation to preventive care' [7].

Developments in DTCGT attracted early attention from academics and medical researchers, [8-10] media [11] and those concerned with regulation [12-14]. While recognising 
DTCGT's potential to empower consumers, the majority emphasised ethical, legal and social issues associated with obtaining genetic information outside healthcare systems. Concern has been expressed about DTCGT tests, questioning accuracy (analytic validity), link to increased disease risk (clinical validity) and whether treatment options or lifestyle changes exist to mitigate or at least manage indicated risk (clinical utility) $[15,16]$.

One key issue with DTCGT has been, and continues to be, the potential for consumer harm, especially if consumers use test results to make significant independent treatment, prevention and lifestyle decisions [17]. Disease predisposition tests do not generate definitive results but rather probabilities, creating the potential for 'unjustified anxiety' from false positive test results and 'false reassurance' from false negative results. Consumers self-interpret results, as advice from trained professionals is generally not a standard component of the DTCGT offering [18]. Even if tests are accurate, consumers generally do not have the required knowledge and skills to interpret and appropriately action test results, and may turn to the healthcare system for assistance [19], shifting the burden back onto public resources [20].

Understanding public reaction to DTCGT is vital to inform considered regulatory, healthcare and consumer protection strategies. Research with the general public is still in its infancy, consisting mainly of unintegrated descriptive studies examining wide-ranging topics (e.g. awareness, attitudes, interest, intentions) across an assortment of samples, primarily US (students, general public, early DTCGT customers). With rising access to global markets and increased promotion, especially online, it is imperative to understand developed, developing and potential markets to assess DTCGT's potential risks and benefits and whether these vary depending on regulatory regimes, healthcare systems and cultural views. Importantly, there is no publicly available cross-jurisdictional research comparing drivers and outcomes such as results comprehension, psychological and behavioural reactions, likelihood of seeking professional healthcare involvement, and willingness to allow company use of submitted DNA. There is also no cross-jurisdictional research directly comparing purchase and purchase intention within or outside one's country of residence.

This study is the first to directly compare public engagement with DTCGT across the more developed market in the US, where the majority of DTCGT companies are located $(n=1000)$, with two relatively newer markets in Australia $(n=1000)$ and the United Kingdom $(n=1014)$ and the emerging Japanese market $(n=1018)$. The study was designed to be cross-sectional, bringing together numerous, often interrelated variables that may influence past and future DTCGT purchase. The core of the survey was the experimental component designed to assess comprehension and psychological and behavioural reactions to hypothetical DTCGT reports that varied according to the type of test (type 2 diabetes, colorectal cancer, drug sensitivity), severity of risk, lifestyle/family history information and validity of genetic results. The survey also included a range of demographic and health-related variables and predictive factors, such as DTCGT familiarity, genetic determinism beliefs, trust in health information sources, privacy concerns, numeric ability and existing healthrelated behaviour.

The study thereby facilitated advanced analyses and nuanced insights relative to measures needed to ensure regulatory and healthcare responses to DTCGT appropriately reflect public concerns and values. Given the study's breadth and complexity, this paper's purpose is to present its design and measures together with the sample characteristics from each countries. We also provide cross country results associated with awareness of DTCGT, willingness to purchase, and whether decisions would be made based on receiving different results that varied across type of disease and severity. We expected that US respondents would be more aware and would demonstrate higher willingness to purchase a test, given the dominance of the US market. However other differences were exploratory given the limited research in Australia, the UK and especially Japan, where there is currently none. Further work is being undertaken to analyse more fully the reasons for country differences to inform effective consumer protection and community engagement.

\section{Materials and methods}

The research design was driven by four main questions: (1) Is there potential for consumer harm, in particular psychological, resulting from engagement with DTCGT? (2) Do DTCGT results motivate behavioural change? (3) What determines familiarity with and intention to purchase DTCGT? and 4) Do responses vary by country, type of test, and respondent? An online survey of US, Australian, Japanese and UK respondents was designed to assess the study's aims. Respondents were sourced by Qualtrics and administered in Australia and the US in March 2015, the UK in September 2015 and Japan in December 2015. Qualtrics provided stringent quality control features such as the ability to screen for dishonest, inaccurate and speedy respondents, use of sophisticated digital fingerprinting to avoid duplication, and compliance with ISO standard and industry standard data protection and security procedures. Quotas ensured country samples were roughly gender and age representative of target populations. 


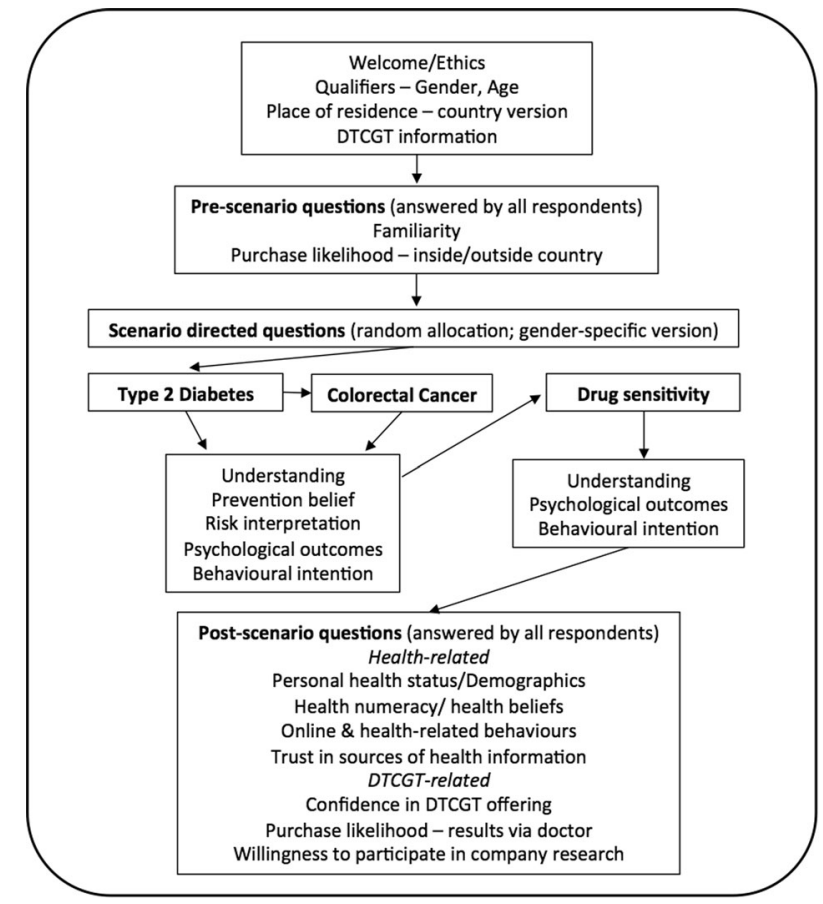

Fig. 1 Experimental design

The experimental component was designed to assess comprehension and potential for psychological detriment and behavioural change, focusing specifically on disease pre-disposition and drug sensitivity (pharmacogenomics). Each respondent was presented with three scenarios involving DTCGT results for named individuals relating to type 2 diabetes, colorectal cancer and sensitivity to a genetic blood-thinning drug. Respondents were presented population average risk and randomised personal risk for the two diseases and metabolisation rate for the drug. Respondents first were asked questions designed to assess understanding, general disease perceptions and risk interpretation for the diseases and understanding for the drug. Respondents were then asked to assume they received comparable results to named individuals and to answer questions designed to measure potential psychological consequences and behavioural intentions in response to results. (see Fig. 1 for a representation of the survey design).

All respondents answered questions before and after the experimental component designed to assess: DTCGT familiarity; purchase and purchase intention; confidence in DTCGT offering; willingness to participate in company research; trust in health information sources; health fatalism; beliefs in genetic determinism; health-related behaviours; and personal health (survey available via authors). All respondents answered the same questions except for those requiring country-specific adaptation (e.g. education, income). The survey used for Japan was available in English and Japanese versions, with translation conducted by professional translators, requiring several iterations to match meaning and context before final approval. The study obtained ethics approval from the University of Tasmania and Osaka University.

\section{Experimental design}

The three scenarios reflect the types of reports currently delivered by DTCGT services. Respondents were allocated gender-specific versions, with male and female names common in each country used. For the two diseases, respondents were randomly assigned low, high or higher risk for their named individual representing 20\% lower, $20 \%$ higher, and $100 \%$ higher than the average population risk (as defined by a major US DTCGT company). Scenarios also included known causal factors-lifestyle for diabetes and family history for colorectal cancer. Respondents were randomly allocated into 1 of 28 possible scenarios, where named individuals either had or did not have causal factors or into control conditions with no additional information. The design of the 28 different scenarios across type of disease, risk and causal factors (for the disease scenarios) and type of result, validity and dose information (for the drug sensitivity scenario) is summarised in Table 1 .

For drug sensitivity, respondents were randomly assigned slow or fast metabolisation rate for named individuals. Scenarios also included information about whether tests were based on small or large numbers of scientific studies (preliminary versus established research as used by a major US company) and whether studies suggested no negative effects from either increasing or decreasing dosage. Respondents were randomly assigned research and negative effect information or received only metabolisation rate, (ten different treatments; See Table 1). Respondents received one treatment each for diabetes, cancer and drug sensitivity, in that order. Randomisation of the 28 treatments was successful, generating near equal numbers ( $n$ per treatment: 108-116 per country).

For each of the three scenarios, respondents were first asked to rate their understanding of results presented. For the two diseases, respondents were asked whether named individuals could prevent the disease, and then to interpret their randomised DTCGT results based on the named individual's likelihood of developing the disease (termed perceived severity) compared with the population average (termed actual severity). Respondents were then asked to assume they received the same results as named individuals and to assess their personal perceived risk of developing the disease; potential psychological distress (ten randomly presented affect states adapted from the Positive and Negative Affect Scale) [21]; and a range of randomly presented behavioural intentions including lifestyle changes (e.g. diet); sharing (e.g. family or online), engagement with 


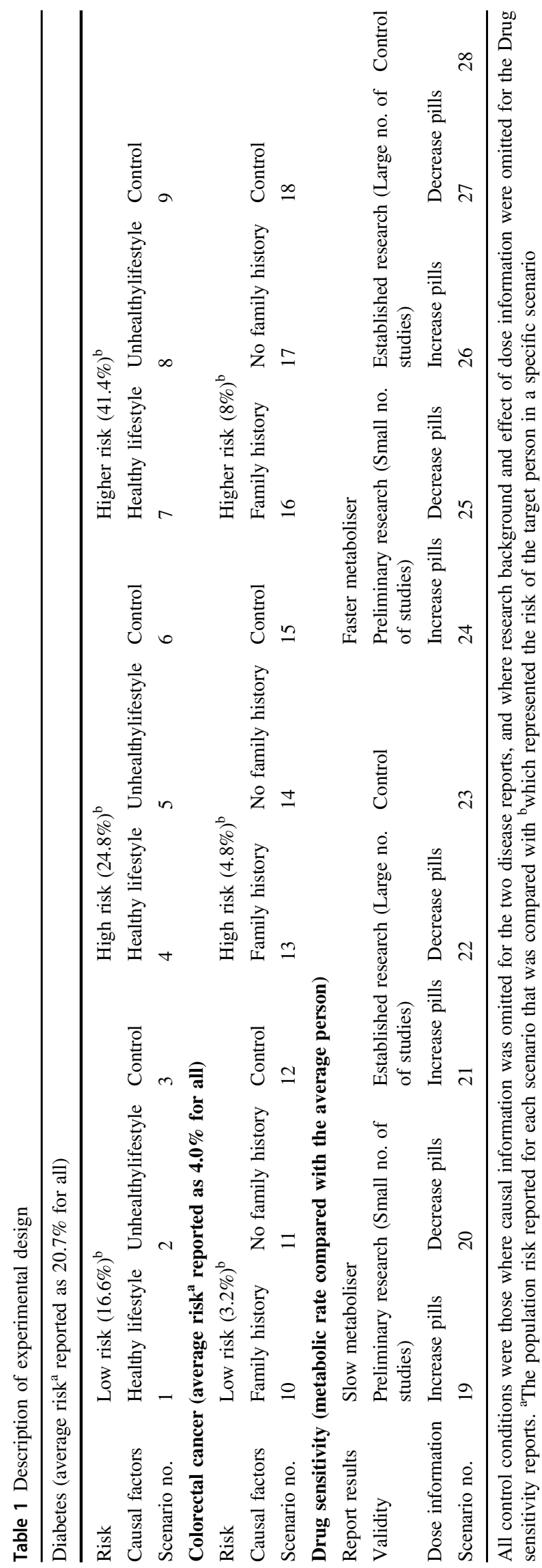

healthcare professionals (e.g. doctors for interpretation); information-seeking (e.g. online) or intention to make no decisions.

For drug sensitivity, respondents were also asked to assume they received the same results as named individuals and whether they would make decisions based on results. They then assessed potential psychological distress (same affect states as above); and indicated whether they would alter their medication regime independently or only after expert advice.

\section{Introductory and post experimental responses}

For quota purposes, respondents were asked at the outset to indicate gender, age and state of residence (based on country of residence). They were presented with a brief description of DTCG to ensure sufficient knowledge to complete the survey. Questions were then asked about presurvey DTCGT familiarity and intention to purchase tests from either onshore or offshore companies. After the experimental component, all respondents assessed their confidence relative to DTCGT (test accuracy, completeness of information; personal ability to interpret results and sharing only with permission) and willingness for their data to be used in company research (freely shared with university researchers; used in company's own research, or sold for profit). Respondents were asked whether they had purchased tests for either themselves or others and likelihood of purchase if DNA was returned via doctors.

A suite of 18 questions was asked relating to health consciousness (health concerns are integrated into daily activities) [22]; health fatalism beliefs (lack of personal control over health and illness) [23]; genetic determinism (belief genetics causes illness); and the influence of lifestyle and family history on diabetes and colorectal cancer development. Six questions were asked to assess recent health-seeking and sharing behaviours (e.g. online selfdiagnosis and sharing in online communities) and five questions concerning trust in health information sources (e.g. family and doctors). Two questions tested health numeracy, one testing risk interpretation and one dosage determination.

\section{Health and demographic background characteristics}

Self-reported health was measured with five questions designed to assess overall health, diet, exercise, family history of the two diseases and whether respondents took prescription medication. The survey ended with basic demographic questions: marital status; education; ethnicity; work status; household income; and number of children under 18 in household and its total size. 
Table 2 Descriptive Statistics for all categorical demographic variables across country

\begin{tabular}{|c|c|c|c|c|c|c|c|c|c|c|}
\hline & \multicolumn{2}{|l|}{ Total } & \multicolumn{2}{|c|}{ Australia } & \multicolumn{2}{|l|}{ US } & \multicolumn{2}{|l|}{ UK } & \multicolumn{2}{|c|}{ Japan } \\
\hline & $n$ & $\%$ & $n$ & $\%$ & $n$ & $\%$ & $n$ & $\%$ & $n$ & $\%$ \\
\hline \multicolumn{11}{|l|}{ Gender } \\
\hline Male & 1973 & 48.9 & 490 & 49.0 & 490 & 49.0 & 495 & 48.8 & 498 & 48.9 \\
\hline Female & 2059 & 51.1 & 510 & 51.0 & 510 & 51.0 & 519 & 51.2 & 520 & 51.1 \\
\hline \multicolumn{11}{|l|}{ Education } \\
\hline Not university educated & 2164 & 53.7 & 561 & 56.1 & 574 & 57.4 & 588 & 58.0 & 441 & 43.3 \\
\hline University educated & 1868 & 46.3 & 439 & 43.9 & 426 & 42.6 & 426 & 42.0 & 577 & 56.7 \\
\hline \multicolumn{11}{|l|}{ Employment status } \\
\hline Paid employment & 2174 & 53.9 & 489 & 48.9 & 528 & 52.8 & 551 & 54.3 & 606 & 59.5 \\
\hline Not in paid employment & 1615 & 40.1 & 435 & 43.5 & 429 & 42.9 & 408 & 40.2 & 343 & 33.7 \\
\hline Student & 243 & 6.0 & 76 & 7.6 & 43 & 4.3 & 55 & 5.4 & 69 & 6.8 \\
\hline \multicolumn{11}{|l|}{ Marital status } \\
\hline Not partnered & 1760 & 43.7 & 407 & 40.7 & 420 & 42.0 & 425 & 41.9 & 508 & 49.9 \\
\hline Partnered & 2272 & 56.3 & 593 & 59.3 & 580 & 58.0 & 589 & 58.1 & 510 & 50.1 \\
\hline \multicolumn{11}{|l|}{ Ethnicity $^{\mathrm{a}}$} \\
\hline Majority & 2843 & 82.5 & 567 & 69.1 & 648 & 74.1 & 855 & 92.2 & 773 & 93.8 \\
\hline Minority & 157 & 4.6 & 3 & 0.40 & 140 & 16.0 & 14 & 1.5 & 0 & 0.0 \\
\hline Outside country & 446 & 12.9 & 251 & 30.6 & 86 & 9.8 & 58 & 6.3 & 51 & 6.2 \\
\hline \multicolumn{11}{|l|}{ Diabetes history } \\
\hline Yes & 1106 & 27.7 & 260 & 26.3 & 384 & 38.6 & 256 & 25.5 & 206 & 20.3 \\
\hline No & 2554 & 63.9 & 606 & 61.4 & 524 & 52.7 & 673 & 67.0 & 751 & 74.1 \\
\hline Unsure & 339 & 8.5 & 121 & 12.3 & 86 & 8.7 & 76 & 7.6 & 56 & 5.5 \\
\hline \multicolumn{11}{|l|}{ Cancer family history } \\
\hline Yes & 355 & 8.9 & 72 & 7.30 & 121 & 12.2 & 56 & 5.6 & 106 & 10.5 \\
\hline No & 3148 & 78.8 & 730 & 74.1 & 744 & 74.8 & 827 & 82.2 & 847 & 83.9 \\
\hline Unsure & 493 & 12.3 & 183 & 18.6 & 130 & 13.1 & 123 & 12.2 & 57 & 5.6 \\
\hline \multicolumn{11}{|l|}{ Prescription medication } \\
\hline No & 2124 & 53.6 & 496 & 50.7 & 430 & 43.9 & 504 & 50.5 & 694 & 69.1 \\
\hline Yes & 1836 & 46.4 & 483 & 49.3 & 549 & 56.1 & 494 & 49.5 & 310 & 30.9 \\
\hline
\end{tabular}

${ }^{a}$ Majority was defined as those who identified as Australian, American, English/British/Welsh/Scottish or Japanese. For Australia, US and UK respondents this also included those indicating "white" or "Caucasian" and "Asian" for Japanese respondents. Minority was defined as black, African American, Latino, and indigenous, while the category "Outside country" were those who identified with a culture outside their country of residence (e.g., German, Middle Eastern, Chinese)

\section{Participants}

Descriptive statistics of all demographic variables across country are shown in Tables 2 and 3. The mean age was similar across countries due to quotas but there were wide levels of variation (i.e., SD's were around 16 years-see Table 2). Overall the sample was fairly representative in terms of age, though all countries were slightly underrepresented by older respondents, particularly Japan [24] http://www.nationmaster.com/country-info/stats/People/ Age-distribution/Median-age. The samples were also representative of those with tertiary qualifications, with the proportion being slightly higher in Japan. The Japanese sample was slightly overrepresented by those with a tertiary education (i.e. $56.7 \%$ compared with $49.5 \%$ in the population) [25].

The sample was not representative of those in paid employment, according to OECD employment rates for 2015 [26]. In 2015, the proportion of Australians between 15 and 65 years in paid employment was $73.6 \%$ (sample: 48.9\%), US $70.6 \%$ (sample: $52.8 \%$ ), UK $74 \%$ (sample: $54.3 \%$ ) and Japan $76.7 \%$ (sample: $59.5 \%$ ). Interestingly household income was reasonably representative for the Japanese sample, but slightly over represented by those on lower incomes in the US, UK and Australia. The median household income category for Australians was $\$ 50 \mathrm{k}-\$ 74 \mathrm{k}$ compared with median population gross household income of $\$ 84,032$ in 2015 [27]; for the US $\$ 50 \mathrm{k}-\$ 74 \mathrm{k}$ compared 
Table 3 Descriptive statistics for all continuous demographic variables across country

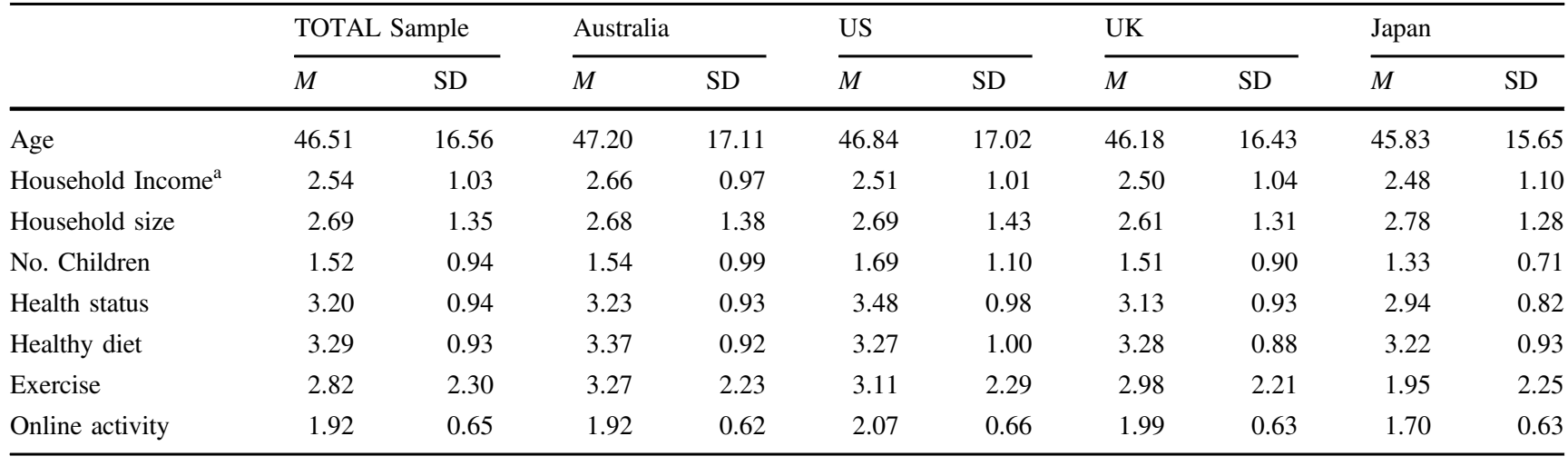

$M$ Mean, SD Standard deviation

${ }^{a}$ Household income for each country was initially eight categories for all except Japan which was nine. To standardise the currencies four income categories were created, where 2SD's below the country's mean was defined as low, 1SD below the mean was Low-medium, 1SD above and including the mean was Medium to high and 2 SD's above the mean as High. Ranges for the other variables were: Age $=18-91$ years, Household size $=1-12$, Number of children $=1-11$ (There were no respondents without children living in the household), Health status $=1$ (poor) -5 (very good), Diet $=1$ (very unhealthy) -5 (very healthy), Exercise $=0-7$ days per week, Online searching $=1$ (never) -3 (regularly). There were no missing values on all variables apart from household income (prefer not to answer option selected). Total $n$ 's were therefore 4032 while for income $n=3665$

to population median of $\$ 57,230$ [28]; the UK $£ 23-34,999$ compared with population median of $£ 25,700$ [29]; and Japan $¥ 5,000,001-¥ 6,000,000$ compared with population median of $¥ 5,743,488$ in 2015 [30].

Cross-country comparisons of demographic variables (and their intercorrelations) were conducted to check the validity of the samples and to provide future insight into possible reasons for why views of DTCGT might vary on a country-specific basis. The results in Table S1 and Fig. S1 (see Supplementary materials) reveal many demographic differences across countries. Not surprisingly there were no age or gender differences as quotas were imposed. Overall US and Japanese citizens appeared to be the most distinct, while Australia and the UK were more similar. Compared with the Western countries, the Japanese sample had higher education, fewer children (though slightly higher household size) and were more likely to be in paid employment and a relationship. Japanese respondents were also less likely to use the Internet, report poorer health and diet, exercise less and report a higher incidence of cancer within their families. Interestingly however, they were less likely than all other countries to be on prescription medication and to have a history of diabetes.

US respondents were similar to the other Western cultures in relation to their demographic background, although they did have the highest number of children living in their households. They were, however, distinctive from all other countries in terms of their increased online activity and health status. While reporting the highest levels of good health and the healthiest diet, they were more likely to be taking prescription medication and to have a family history of both diabetes and cancer. The UK and Australia appeared to be most similar, with relatively few significant differences between them. However, Australians were slightly less likely to be in paid employment, and reported lower online activity, slightly better health status, healthier diets, and increased exercised than UK respondents. US respondents were also significantly $(p<0.001)$ more likely to have already purchased a DTCGT either for themselves or someone else $(21.3 \%)$ than all other countries who were similar (Australia: 9.5\%; UK: 9.3\%; Japan: 8.3\%).

\section{Statistical analysis}

All analyses were computed via SPSS Version 25. A series of univariate analyses of variance (ANOVA) tests were computed to assess country differences in mean levels of familiarity, intention to purchase and the likelihood that no decisions would be made in response to scenarios. In relation to familiarity, a one-way ANOVA with familiarity as the dependent variable (DV) and country as the independent variable (IV) was computed with post hoc comparisons (Student Newman Keuls) used to explore specific differences. A 4 (country) by 3 (source of test: inside country, outside country, via doctor) mixed design ANOVA was conducted to explore the differences in intention to purchase across country and source. One-way ANOVA's were computed to investigate the direction of the interaction by comparing mean intention differences across test sources within each country separately.

To assess whether respondents would act on the results presented to them, we compared the likelihood that no decisions would be made on the test results across countries and scenarios (i.e., If you took a direct-to-consumer genetic 
test for Type 2 diabetes/colorectal cancer and your test results were the same as Jennifer's, how likely is it that you would not make any decisions based on the test results). Specifically, the impact of country, risk and causal factors on the likelihood of making no decisions in response to the diabetes and colorectal cancer scenarios were assessed by two, 4 (Country) by 3 (Risk) by 3 (Causal factors) betweengroups ANOVAs. For the drug sensitivity scenario, two separate ANOVA's were computed as the control groups for validity and dose information were not independent (see Table 1). The first consisted of a 4 (country) $\times 2$ (Report results) $\times 3$ (Validity) design, and the second a 4 (country) $\times 2$ (Report results) $\times 3$ (Dose) design.

\section{Results}

The mean familiarity scores displayed in Fig. 2 show all countries displayed low familiarity with DTCGTs. Apart from the US, the UK, Australia and particularly Japanese respondents' average familiarity score was below two. The US average was above two indicating a slight familiarity on average. Significant variation $(p<0.001)$ across countries

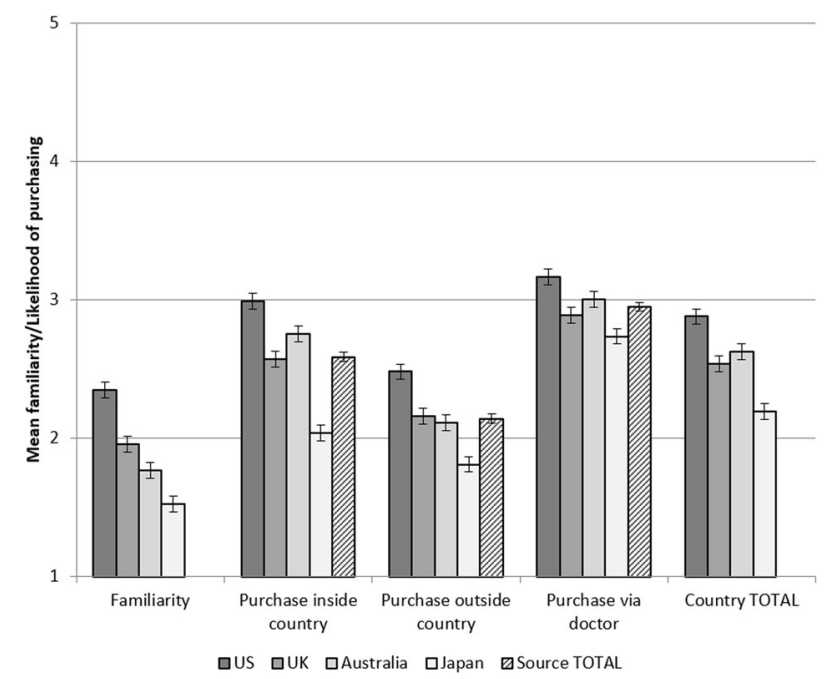

Fig. 2 Mean level of familiarity and intention to purchase across country. Bars represent the $95 \%$ confidence intervals of the mean. For Familiarity (Prior to starting this survey, how familiar were you with direct-to-consumer genetic testing?), $1=$ Not familiar, $2=$ Slightly familiar, $3=$ Somewhat familiar, $4=$ Moderately familiar and $5=$ Extremely familiar. For intention ("What would you say is the likelihood of you purchasing a direct-to-consumer genetic test from a company located INSIDE/OUTSIDE your country of residence?; How likely it would be that you would purchase a direct-to-consumer genetic test if you provided your DNA sample to the company but the company returned your test results to your doctor?) $1=$ Extremely unlikely, $2=$ Unlikely, $3=$ Neutral, $4=$ Likely and $5=$ Extremely likely. Source TOTAL is the mean intention for each source averaged across country. Country TOTAL is the mean intention for each country averaged across source was found, with post hoc comparisons revealing familiarity levels differed significantly across all countries (at $p<$ 0.001). US respondents reported the highest level of familiarity, followed by UK, Australian and then Japanese respondents.

Averaged across country, all respondents demonstrated low intentions to purchase a DTCGT (See Country total in Fig. 2). The effect of country was significant (at $p<0.001$ ) with intention being highest for US, followed by Australian, UK and Japanese respondents (See Fig. 2). The difference between Australia and the UK was weaker $(p=0.035)$ relative to all other country comparisons (all significant at $p<0.001)$. Comparisons of intention across the three sources of DTCGT were also significant. Intention to purchase a DTCGT was highest when the purchased test was returned to a doctor, followed by purchasing from a company inside one's own country, which was significantly higher than intention to purchase outside one's country of residence (all comparisons were significant at $p<0.001$ ). The interaction was also significant $(p<0.001)$, suggesting an increased tendency to purchase when the results are returned to a doctor compared with a company (inside one's country) was exacerbated for Japan. For the US, UK and particularly Australia, the difference in intention was greater between inside and outside of their countries. Thus the results suggest that the western countries and especially Australia, are more concerned than the Japanese about tests originating from overseas companies (see Fig. S2 in Supplementary materials).

\section{Decisions}

For both the diabetes and colorectal cancer scenarios all main effects were significant (all at $p<0.001$ ), but there were no significant interactions. Post hoc comparisons for the main effect of risk revealed all were significant (at $p<$ 0.001) for the diabetes and colorectal cancer scenarios. Respondents were significantly more likely to report that they would make no decisions when the risk was low (Diabetes: $M=2.99, \mathrm{SE}=0.03$; Cancer: $M=3.18$; $\mathrm{SE}=$ 0.03 ), than when the risk was high (Diabetes: $M=2.84, \mathrm{SE}$ $=0.03$; Cancer: $M=2.99, \mathrm{SE}=0.03$ ) and higher (Diabetes: $M=2.63, \mathrm{SE}=0.03$; Cancer: $M=2.79, \mathrm{SE}=0.03$ ). Comparisons across causal factors for diabetes found that no decisions were most likely to occur in response to a healthy lifestyle $(M=2.92, \mathrm{SE}=0.03)$ or when no information was provided $(M=2.84, \mathrm{SE}=0.03)$ compared with an unhealthy lifestyle $(M=2.70, \mathrm{SE}=0.03)$. A similar pattern was found for the cancer scenario where no decisions were more likely in response to no family history $(M$ $=3.03, \mathrm{SE}=0.03)$ or no information $(M=3.04, \mathrm{SE}=$ 0.03 ) compared with when the target person was described as having a family history of cancer $(M=2.89, \mathrm{SE}=0.03)$. 


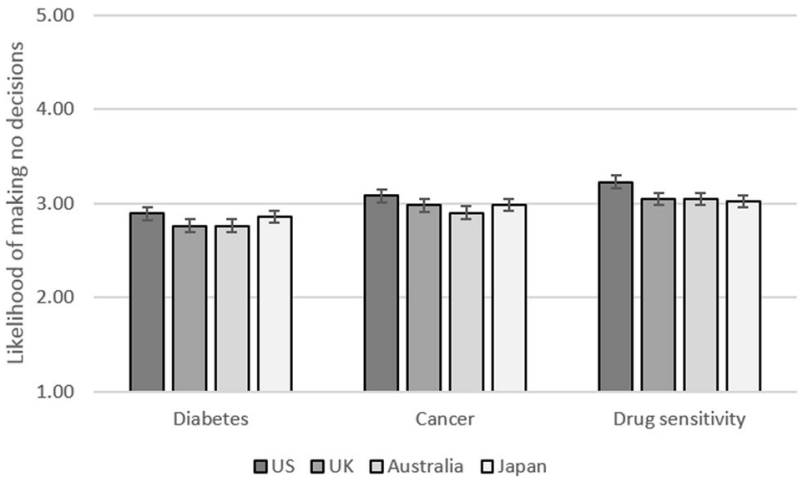

Fig. 3 Mean likelihood of making no decisions score across country. High scores $=$ Higher likelihood of making no decisions in response the scenario. Bars represent the $95 \%$ confidence intervals of the mean

Post hoc comparisons across countries for both scenarios revealed the only significant difference was between the US and Australia. As the means in Fig. 3 show, US respondents were more likely to make no decisions based on either the diabetes or cancer scenarios than Australians.

For the drug sensitivity scenario, the first ANOVA revealed no significant effects apart from a significant (at $p$ $<0.001)$ main effect for country. The second however revealed significant main effects for country $(p<0.001)$ and dose $(p=0.009)$, as well as a significant country $\times$ dose interaction, $\left.F(6,4008)=2.38, p=0.028, \eta^{2}=.004\right)$. Post hoc comparisons for country revealed that US respondents were more likely to make no decisions in response to the drug sensitivity scenario compared with all other countries (all at $p<0.001$ ) whom were statistically similar (see Fig. 3). The interaction suggested that significant differences across dose occurred only for US respondents. No decisions were more likely (at $p<0.001$ ) to occur when the evidence given was associated with increasing the dose compared with decreasing it and providing no evidence (i.e., control condition) (See Fig. 4 for the difference in means).

\section{Discussion}

Regulating in areas of emerging or rapidly developing technologies, with evolving industry structures, presents particular challenges $[4,31]$. As a general principle, regulation should be ethically and legitimately appropriate, reflect consensus opinion accommodating differing belief systems to ensure regulatory acceptance, while being responsive to technological developments (future-proofed) [32]. A recurring theme in the DTCGT literature is that ethical, legal and social issues involved are sufficiently serious to require regulation [33-35]. As the majority of activity and development in the DTCGT sector is centred in the US but available online, resulting jurisdictional

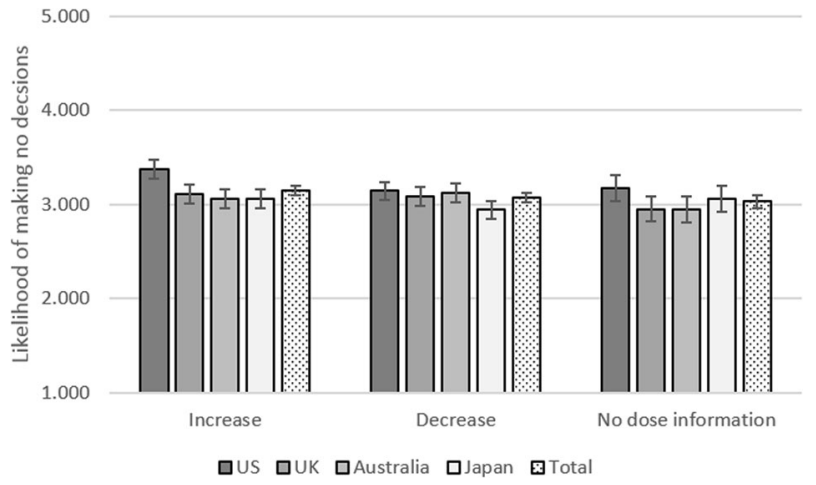

Fig. 4 Mean decision score across country and dose information. High scores $=$ Higher likelihood of making no decisions in response the scenario. Bars represent the $95 \%$ confidence intervals of the mean

challenges require consideration at an international level [36]. An understanding of public opinion across different countries on the range of issues is crucial to inform development of appropriate national and international regulatory frameworks. This project provides a foundation for future comparative analyses associated with DTCGT in newer markets, with different cultural perspectives and healthcare systems to those in the more established US market.

As expected, our findings suggest that awareness of DTCGT and intention to purchase a test were substantially higher in the established US market than the newer markets of the UK, Australia and especially Japan. Suggesting that within jurisdiction regulatory approaches are a priority, respondents from all countries (including the US) reported being more likely to purchase a test from a company within their own country and even more likely if it was purchased via a doctor. However our results also suggest that intention to purchase a test from an international company is likely to grow with increasing awareness, thereby requiring harmonisation at the international level. This is particularly the case in countries like Japan where awareness was very low and the effect of a company's location on respondents' intention was less pronounced. Moreover, results from the experimental component of our study suggest strongly that respondents are more likely to make decisions to act on test results rather than doing nothing. Particularly if genetic results or lifestyle factors communicate higher predictive risk for developing a disease.

The next logical step in this study is to determine the potential for harm or benefit, establishing the nature of, and the reasons behind decisions taken in response to different scenarios in different countries. The reasons for the differences found in this research need to be examined, especially the intriguing result that US respondents were less likely to make active decisions based on test results relating to drug sensitivity than Australians, especially if they received further information relating to the validity of a test. Analysis of the demographic variables across the four countries 
reveals significant potential to generate valuable future insights into the reasons underlying potential reactions as well as cross-cultural differences. Indicating potential for generalisability, the samples are relatively representative of the US, UK, Australian and Japanese populations, and sufficiently heterogeneous to allow within-country comparisons. All were representative in relation to gender and education, and reasonably representative in terms of age, with the exception of Japan, which was slightly over represented by younger respondents.

Providing confidence in the generalisability of the samples, many of the identified demographic differences reflected actual differences in the populations. For example, the higher rates of respondents with university/college educations and those in employment amongst the Japanese population compared with the three other countries was reflected in the sample differences $[25,26]$. The higher incidence of type 2 diabetes in the US (10.8\%) compared with the other three countries (Australia: 5.2\%, UK: $4.3 \%$, Japan: 5.7\%) https://data.worldbank.org/indicator/sh.sta.dia b.zs, higher rates of colorectal cancer in Japan and the US compared with Australia and the UK [37], and higher use of prescription medication amongst US respondents [38] were also reflected in the pattern of results.

The four sample jurisdictions were, however, overrepresented by those not in paid employment and, with the exception of the Japanese sample, those with lower household incomes. This may reflect the nature of the online panel respondents, who are active Internet users [39] and may be more motivated by small incentives (e.g. reward points). However, this study required Internet-literate respondents, confirmed by respondents' relatively high Internet usage (especially US). While these factors may present limitations, more recent research suggests demographic differences between online panel respondents and those recruited by other methods (e.g. telephone) may be diminishing with increased household Internet penetration [40], and companies (including Qualtrics) partnering with other panel providers to allow access to larger, more diverse or targeted populations. Sample diversity and representativeness in relation to key variables such as gender, age and education in this study are indicative of improvements in online recruitment practices.

There is now an emerging body of empirical studies of consumer interactions with DTCGT [41-43], yet few commentators have made recommendations on regulatory or oversight requirements, particularly in relation to crossjurisdictional challenges $[44,45]$. The results of this fourcountry cross-jurisdictional DTCGT study provide a basis to inform substantive recommendations in relation to ethical, legal and social issues, at least in the four countries studied. Finally, this study can provide an important opportunity and international template to further investigate
DTCGT engagement with respondents in other jurisdictions with differing demographic profiles, legal and healthcare systems, regulatory regimes, and cultural traditions.

Supplementary information is available at European Journal of Human Genetics' website.

Acknowledgements Experimental design, survey development and Australia and US data collection were completed as part of JC's PhD, supervised equally by DN, CC and DC. JC collected UK and Japanese data on behalf of the Centre for Law \& Genetics and Osaka University respectively. CC and JC prepared the initial draft with all authors contributing to the final article. JW programmed the survey and contributed to specific data preparation, analysis and literature review for this article. NY and KK contributed to survey translation. This research was funded by the Australian Research Council Discovery Grant Personalised Medicine in the Age of Genomic Medicine DP11010069 (AU/US); Centre for Law \& Genetics, UTAS Strategic Grant (UK); Graduate School of Medicine, Osaka University (Japan); and Swinburne University (survey assistance). We would like to thank all survey respondents for their time and considered input.

\section{Compliance with ethical standards}

Conflict of interest The authors declare that they have no conflict of interest.

Publisher's note Springer Nature remains neutral with regard to jurisdictional claims in published maps and institutional affiliations.

\section{References}

1. Wagner J, Cooper J, Sterling R, Royal C. Tilting at windmills no longer: a data-driven discussion of DTC DNA ancestry tests. Genet Med. 2012;14:583-93.

2. The Guardian. Spit parties: Genetic testing becomes a social activity. 18 September 2008. https://www.theguardian.com/ science/blog/2008/sep/18/genetic.testing.

3. Leachman S, MacArthur D, Angrist M, Gray S, Bradbury A, Vorhaus D. Direct-to-consumer genetic testing: personalized medicine in evolution. Genom Law Rep. 2011 34-40. http://www. genomicslawreport.com/wpcontent/uploads/2011/06/ASCODTC-Abstract.pdf.

4. Chalmers D, Nicol D, Otlowski M, Critchley C. Personalised medicine in the genome era. J Law Med. 2013;20:577-94.

5. Ramani D, Saviane C. DCGT: the individual's benefits above all. J Sci Commun. 2011;10:C05.

6. Foster M, Mulvihill J, Sharp R. Evaluating the utility of personal genomic information. Genet Med. 2009;11:570-4.

7. Free State Reporting, Inc., U.S. Department of Health and Human Services, Food and Drug Administration, Molecular and Clinical Genetics Panel, Gaithersburg, Maryland, March 8-9, 2011, 168. Presentation Ashley Gould, General Counsel, 23andMe, Inc.

8. Hudson K. Genetic testing oversight. Science. 2006;313:1853.

9. Kaye J. The regulation of direct-to-consumer genetic tests. Hum Mol Genet. 2008;17:R180-R183.

10. Hogarth S, Javitt J, Melzer D. The current landscape for direct-toconsumer genetic testing: legal, ethical and policy issues. Annu Rev Genom Hum Genet. 2008;9:161-82.

11. Lynch J, Parrott A, Hopkins R, Myers M. Media coverage of direct-to-consumer genetic testing. J Genet Counsel. 2011;20: 486-94. 
12. Australian Law Reform Commission and Australian Health Ethics Committee, Essentially yours: the protection of human genetic information in Australia. Report No. 96. 2003.

13. Human Genetics Commission, Genes direct: ensuring the effective oversight of genetic tests supplied directly to the public. 2003; More genes direct: a common framework of principles for directto-consumer genetic testing services. 2007.

14. Direct-to-consumer Genetic Testing for Health-related purposes in the European Union. Policy Report 18. 2012.

15. Kalf R, Mihaescu R, Kundu K, de Knijff P, Green R, Janssens C. Variations in predicted risks in personal genome testing for complex diseases. Genet Med. 2013;16:85-91.

16. Heald B, Edelman E, Eng C. Prospective comparison of family medical history with personal genome screening for risk assessment of common cancers. Eur J Hum Genet. 2012 20: 547-51.

17. Bansback N, Sizto S, Guh D, Anis A. The effect of direct-toconsumer genetic tests on anticipated affect and health seeking behaviors: a pilot survey. Genet Test Mol Biomark. 2012;16: 1165-71.

18. Howard H, Borry P. Survey of European clinical geneticists on awareness, experiences and attitudes towards direct-to-consumer genetic testing. Genome Med. 2013;5:45-56.

19. Brett G, Metcalfe S, Amor D, Halliday J. An exploration of genetic health professionals' experience with direct-to-consumer genetic testing in their clinical practice. Eur $\mathrm{J}$ Hum Genet. 2012;20:825-30.

20. Giovanni M, Fickie M, Lehman L, Green R, Meckley L, Veenstra $\mathrm{D}$, et al. Health-care referrals from direct-to-consumer genetic testing. Genet Test Mol Biomark. 2010;14:817-9.

21. Watson D, Clark L, Tellegan A. Development and validation of brief measures of positive and negative affect: The PANAS scales. J Personal Soc Psychol. 1988;54:1063-70.

22. Jayanti R, Burns A. The antecedents of preventive healthcare behavior: an empirical study. Acad Mark Sci J. 1998:26:6-15.

23. Fairchild R. Fatalism and health behaviors: exploring the context for clinician-patient interactions. Ann Nurs Pract. 2015;2: 1032-6.

24. World Bank staff estimates based on age/sex distributions of United Nations Population Division's World Population Prospects, 2017 Revision: https://data.worldbank.org/indicator/SP. POP.TOTL.MA.ZS?locations=AS-AU-JP-GB-US.

25. OECD, Adult education level (indicator). 2018; https://doi.org/10. 1787/36bce3fe-en.

26. OECD, Employment rate (indicator). 2018; https://doi.org/10. 1787/1de68a9b-en.

27. Australian Bureau of Statistics, http://abs.gov.au/householdincome.
28. United States Census Bureau, https://www.census.gov/library/ publications/2016/demo/p60-256.html.

29. Office of National Statistics, https://www.ons.gov.uk/ peoplepopulationandcommunity/personalandhouseholdfinances/ incomeandwealth/bulletins/householddisposableincomeandinequa lity/financialyearending 2015 .

30. Statistics Japan, http://www.stat.go.jp/english/info/news/20160420. html.

31. Editorial. Direct-to-consumer genetic testing. The Lancet. 2012;380:76

32. Brownsword R, Goodwin M. Law and the technologies of the twenty-first century. Cambridge University Press; 2012.

33. Wasson K. Consumer alert: ethical issues raised by the sale of genetic tests directly to consumers. Am J Bioethics. 2008;8:16-8.

34. Nuffield Council of Bioethics, Medical profiling and online medicine: the ethics of 'personalised healthcare in a consumer. 2010.

35. Caulfield T, Chandrasekharan C, Joly Y, Cook-Deegan R. Harm, hype and evidence: ELSI research and policy guidance. Genome Med. 2013;5:21. http://genomemedicine.com/content/5/2/21.

36. Borry P, Hellemondt R, Sprumont D, Jales C, Rial-Sebbag E, Spranger T, et al. Legislation on direct-to-consumer genetic testing in seven European countries. Eur J Hu Genet. 2012;20:715-21.

37. Torre L, Siegel R, Ward E, Jemal A. Global cancer incidence and mortality rates and trends-an update. Cancer Epidemiol Prev Biomark. 2016;25:16-27.

38. Squires D, Anderson C. US health care from a global perspective: spending, use of services, prices, and health in 13 countries. The Commonwealth Fund. 2015;15:1-16.

39. Baker R, Blumberg S, Brick M, Couper M, Courtright M, Dennis $\mathrm{JM}$, et al. AAPOR report on online panels. Public Opin. Q. 2010;74:711-81.

40. Callegaro C, Baker R, Bethlehem J, Goritz A, Krosnick J, Lavrakas $\mathrm{P}$. editors, Online panel research: data quality perspective. 2014; John Wiley \& Sons, 2.

41. Bloss C, Schork N, Topo, E. Effect of direct-to-consumer genomewide profiling to assess disease risk. $\mathrm{N}$ Engl $\mathrm{J}$ Med. 2011;364:524-34.

42. Wasson K, Sanders NT, Hogan NS, Cherny S, Helzlsouer KJ. Primary care patients' views and decisions about, experience of and reactions to direct-to-consumer genetic testing: a longitudinal study. J Community Genet. 2014;4:495-505.

43. Bollinger JM, Green R, Kaufman D. Attitudes about regulation among direct-to-consumer genetic testing customers. Genet Test Mol Biomark. 2013;17:424-8.

44. Javitt G, Katsanis S, Scott J, Hudson K. Developing the blueprint for a genetic testing registry. Public Health Genom. 2010;13:95-105.

45. Griggs L. Direct-to-consumer genetic testing: the double helix unleashed, problem or panacea? J Law Med. 2012;20:464-9. 